\title{
Elevated Blood Pressure in Acute Ischemic Stroke: Comment and Reply
}

\author{
Shuping Liu Chengyan Li Tao Li \\ Department of Neurology, Renmin Hospital of Wuhan University, Wuhan, Hubei Province, PR China
}

It is a great honor that our academic issue has gained widespread attention. We thank Dr. Vijay K. Sharma for his thoughtful comments. We had carefully read the Editorial 'Elevated Blood Pressure in Acute Ischemic Stroke - Treat or Leave?' [1]. First, Dr. Vijay K. Sharma explained why blood pressure (BP) should not be actively lowered in acute ischemic stroke (AIS) BP tends to normalize spontaneously within hours or days after AIS onset [2] and higher BP can avoid any further reduction of the cerebral blood flow [3]. Then, he pointed out the adverse effects of high BP, such as higher rates of death or dependency, poor rates of recanalization with intravenous thrombolysis [4], and higher risk of symptomatic intracranial hemorrhage after systemic thrombolysis [5]. We agree with these views above, the haunting contradictions have baffled many clinicians and that's why we make our meta-analysis. Finally, Dr. Vijay K. Sharma concluded that some definitive answers about the role of early intensive BP control in AIS might be obtained from the ongoing Enhanced Control of Hypertension and Thrombolysis Stroke Study (ENCHANTED) trial [6]. Indeed, the ENCHANTED trial can resolve some questions in AIS patients with thrombolysis therapy, but not in non-thrombolysis patients. In addition, some other vital questions require to be resolved urgently: the optimal target of BP lowering, the best time to start lowering BP and whether the severity of stroke play a role, as have been touched upon in our discussion section [7].

Our meta-analysis aimed to investigate the safety and effect of early BP lowering (started within the first $48 \mathrm{~h}$ ) after AIS on the outcome [7]. Our findings most likely are applicable for a majority of patients who do not receive intravenous thrombolytic therapy, because most of the included studies had excluded patients with thrombolytic therapy, although 3 trials did not provide the percentage of patients receiving thrombolytic therapy. The proportion of patients is very low according to recent reports - about $2.4-5.2 \%$ in recent reports from the USA [8] registry and $1.6 \%$ in the China National Stroke Registry [9]. In this respect, our analysis is meaningful. Of course, we had other advantages, which had been emphasized in our discussion section, to make our analysis more powerful.

Dr. Vijay K. Sharma had raised 2 questions about our study. They were about the included studies being limited by the late recruitment (many hours after stroke onset) and smaller BP difference between the active and control arms.

We had already explicitly explained in our discussion section with respect to the first question. We cannot deny that onsetto-treatment time could play a role. We also speculated that timely hypertension control in the super-acute phase of AIS will contribute to more effective thrombolysis; the earlier the treatment given, the greater the proportional benefit. However, our meta-analysis is done on the basis of existing valuable evidence; therefore, we need more and larger RCTs to resolve the following question: what is the best time to start lowering BP?

We think the second question is inappropriate. In our inclusive criteria, we clearly pointed out that the BP was significantly different between the 2 groups after treatment. Statistical power is defined as the probability to find differences that are statistically different. Therefore, our study has sufficient power to assess the effects of early BP lowering (started within the first $48 \mathrm{~h}$ ) after AIS on the outcome.

\section{Acknowledgment}

This work was supported by grants from the Natural Science Foundation of China (81271364). The sponsors played no role in the study design, data collection and analysis or in the decision to submit the article for publication.

\section{Disclosure Statement}

The authors declare no financial or other conflicts of interest.

\section{KARGER}

E-Mail karger@karger.com

www.karger.com/ced
(C) 2016 S. Karger AG, Base

1015-9770/16/0414-0103\$39.50/0
Prof. Associate Prof. Chengyan Li

Department of Neurology

Renmin Hospital of Wuhan University

Wuhan 430060, Hubei Province (PR China)

E-Mail lcyprof@sina.com 


\section{References}

1 Sharma VK: Elevated blood pressure in acute ischemic stroke - treat or leave? Cerebrovasc Dis 2016;41:101-102.

2 Willmot M, Leonardi-Bee J, Bath PM: High blood pressure in acute stroke and subsequent outcome: a systematic review. Hypertension 2004;43:18-24.

3 Powers WJ: Acute hypertension after stroke: the scientific basis for treatment decisions. Neurology 1993;43(3 pt 1):461-467.

4 Tsivgoulis G, Saqqur M, Sharma VK, Lao AY, Hill MD, Alexandrov AV: Association of pretreatment blood pressure with tissue plasminogen activator-induced arterial recanalization in acute ischemic stroke. Stroke 2007;38: 961-966.
5 Leonardi-Bee J, Bath PM, Phillips SJ, Sandercock PA: Blood pressure and clinical outcomes in the international stroke trial. Stroke 2002;33:1315-1320.

6 Huang Y, Sharma VK, Robinson T, et al: Rationale, design, and progress of the enhanced control of hypertension and thrombolysis stroke study (ENCHANTED) trial: an international multicenter $2 \times 2$ quasi-factorial randomized controlled trial of low- vs. standarddose rt-PA and early intensive vs. guideline-recommended blood pressure lowering in patients with acute ischaemic stroke eligible for thrombolysis treatment. Int J Stroke 2015;10:778-788.
7 Liu S, Li C, Li T, Xiong J, Zhao X: Effects of early hypertension control after ischaemic stroke on the outcome: a meta-analysis. Cerebrovasc Dis 2015;40:270-278.

8 El Khoury R, Jung R, Nanda A, et al: Overview of key factors in improving access to acute stroke care. Neurology 2012;79(13 suppl 1):S26-S34.

9 Wang Y, Liao X, Zhao X, et al; China National Stroke Registry Investigators: Using recombinant tissue plasminogen activator to treat acute ischemic stroke in China: analysis of the results from the Chinese national stroke registry (CNSR). Stroke 2011;42: 1658-1664. 